\section{International Scientific Journal Theoretical \& Applied Science}

Nikolay Vasilevich Penshin candidat of economic sciences, Head of the Department "Organization of transportation and road safety" Tambov state technical University, Russia avtobd@mail.ru

Victor Yurievich Ivlev

Undergraduate, Mechanical engineer Aor Nekrasovskoe RTP, city of Rasskazovo, Russia victor.pshenihniy_7@mail.ru

SECTION 27. Transport.

\title{
MONITORING ROAD SAFETY IN THE CITY OF TAMBOV
}

Abstract: In the Tambov region, road transport occupies one of leading positions in the economy. At the present time for a comprehensive solution of problems of road transport Tambov region implemented the "Program of improvement and development of road network in the Tambov region".

Key words: traffic accident, dynamics, analysis.

Language: Russian

Citation: Penshin NV, Ivlev VY (2015) MONITORING ROAD SAFETY IN THE CITY OF TAMBOV. ISJ Theoretical \& Applied Science 12 (32): 92-95.

Soi: http://s-o-i.org/1.1/TAS-12-32-17 Doi: crossef http://dx.doi.org/10.15863/TAS.2015.12.32.17

\section{УДК 502.7}

\section{МОНИТОРИНГ БЕЗОПАСНОСТИ ДОРОЖНОГО ДВИЖЕНИЯ В ГОРОДЕ ТАМБОВЕ}

Аннотация: В Тамбовской области автомобильный транспорт занимает одну из ведущих позиций $в$ экономике. В настоящее время для комплексного решения проблем работы автомобильного транспорта Тамбовской области реализуется "Программа совершенствования и развития сети автомобильньх дорог Тамбовской области".

Ключевые слова: дорожно-транспортное происществие, динамика, анализ.

Для Тамбовской области современная и передовая транспортная инфраструктура - это поистине дорога в будущее. Она имеет стратегическое значение для экономического роста и качественного перехода экономики к инновационному пути развития, для повышения трудовой мобильности и возможностей коммуникации. В транспортной системе Тамбовской области сеть автомобильных дорог является одним из важнейших элементов. На территории Тамбовской области дорог общего пользования 5670,8 км, из них муниципального значения 3670,5 км. Интенсивность движения возрастает по причине быстрых темпов развития автомобильного парка области. Если в 1990 году насчитывалось (по данным ГИБДД) 108,5 тыс.автомобилей, то к началу 2015 года их количество увеличилось почти в 4 раза и составило 410,7 тыс.единиц.

Поэтому одной из важнейших задач является обеспечение безопасности дорожного движения. На решение этой проблемы направлен целый комплекс мероприятий, предусмотренный муниципальной программой «Повышение безопасности дорожного движения в городе Тамбове».

Проанализируем безопасность дорожного движения в городе Тамбов.

В текущем году на территории города Тамбова зарегистрировано 19 дорожнотранспортных происшествий по вине нетрезвых водителей, в которых 2 человека погибли и 30 получили ранения. Несмотря на существенное снижение $(-45,7 \%)$ количества аварий с данной категорией участников дорожного движения по сравнению с аналогичным периодом прошлого года, состояние аварийности по вине нетрезвых водителей вызывает особую тревогу. 


\begin{tabular}{l|lr|ll|ll} 
& ISRA (India) & $=\mathbf{1 . 3 4 4}$ & SIS (USA) & $=\mathbf{0 . 9 1 2}$ & ICV (Poland) & $=\mathbf{6 . 6 3 0}$ \\
Impact Factor: & ISI (Dubai, UAE) $=\mathbf{0 . 8 2 9}$ & PUHI (Russia) $=\mathbf{0 . 1 7 9}$ & PIF (India) & $=\mathbf{1 . 9 4 0}$ \\
& GIF (Australia) & $=\mathbf{0 . 5 6 4}$ & ESJI (KZ) & $=\mathbf{1 . 0 4 2}$ & & \\
JIF & $=\mathbf{1 . 5 0 0}$ & SJIF (Morocco) & $\mathbf{2 . 0 3 1}$ & & \\
\hline
\end{tabular}

Статистика ДТП за 2013-2015 гг.

Таблица 1

\begin{tabular}{|c|c|c|c|c|c|}
\hline \multicolumn{2}{|c|}{ ДТП } & \multicolumn{2}{|c|}{ Погибло } & \multicolumn{2}{|c|}{ Ранено } \\
\hline абс & $\pm \%$ к АППГ & абс & $\pm \%$ к АППГ & абс & $\pm \%$ к АППГ \\
\hline \multicolumn{6}{|c|}{2015 г } \\
\hline 1280 & $-36,4$ & 142 & $-43,2$ & 1791 & $--35,2$ \\
\hline \multicolumn{6}{|c|}{2014 г } \\
\hline 1848 & $-2,6$ & 235 & 15,8 & 2544 & $-4,3$ \\
\hline \multicolumn{6}{|c|}{2013 г } \\
\hline 1896 & 0,2 & 203 & $-9,8$ & 2640 & 1,7 \\
\hline
\end{tabular}

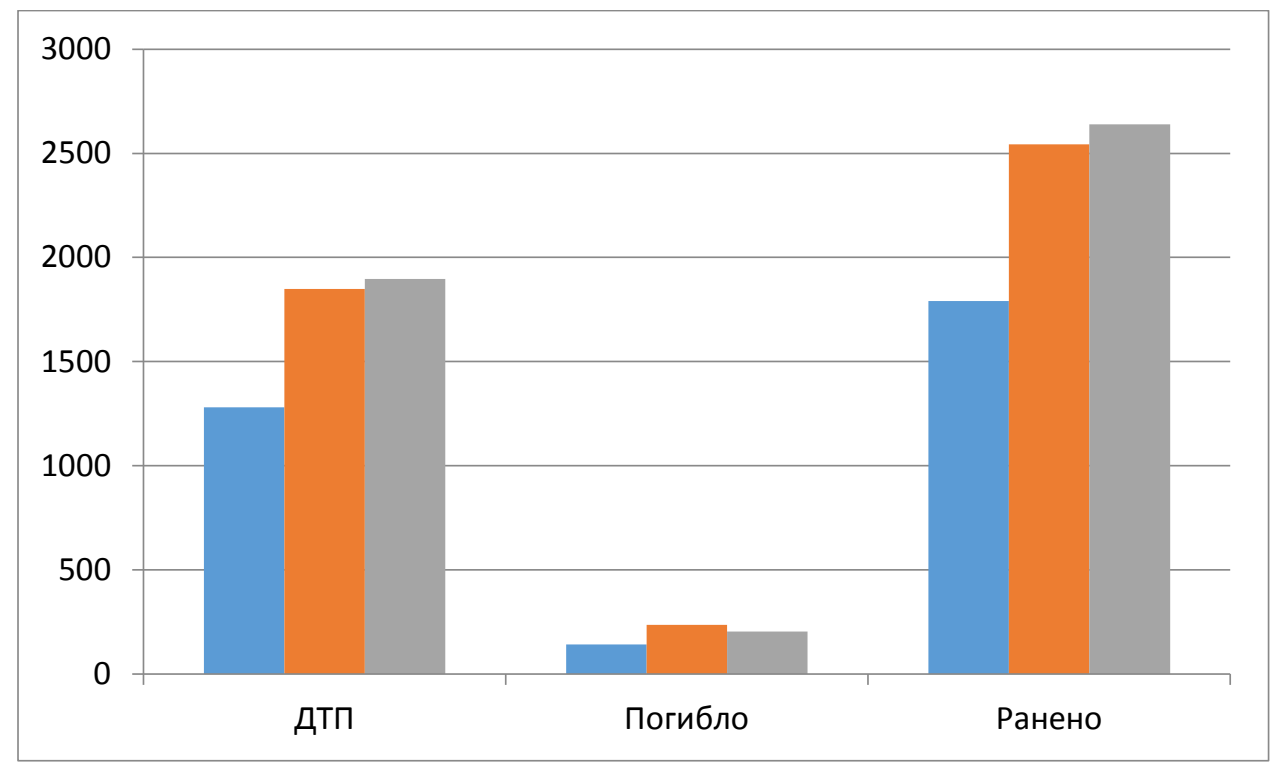

Рисунок 1 - Динамика аварийности за 2013-2015 гг.

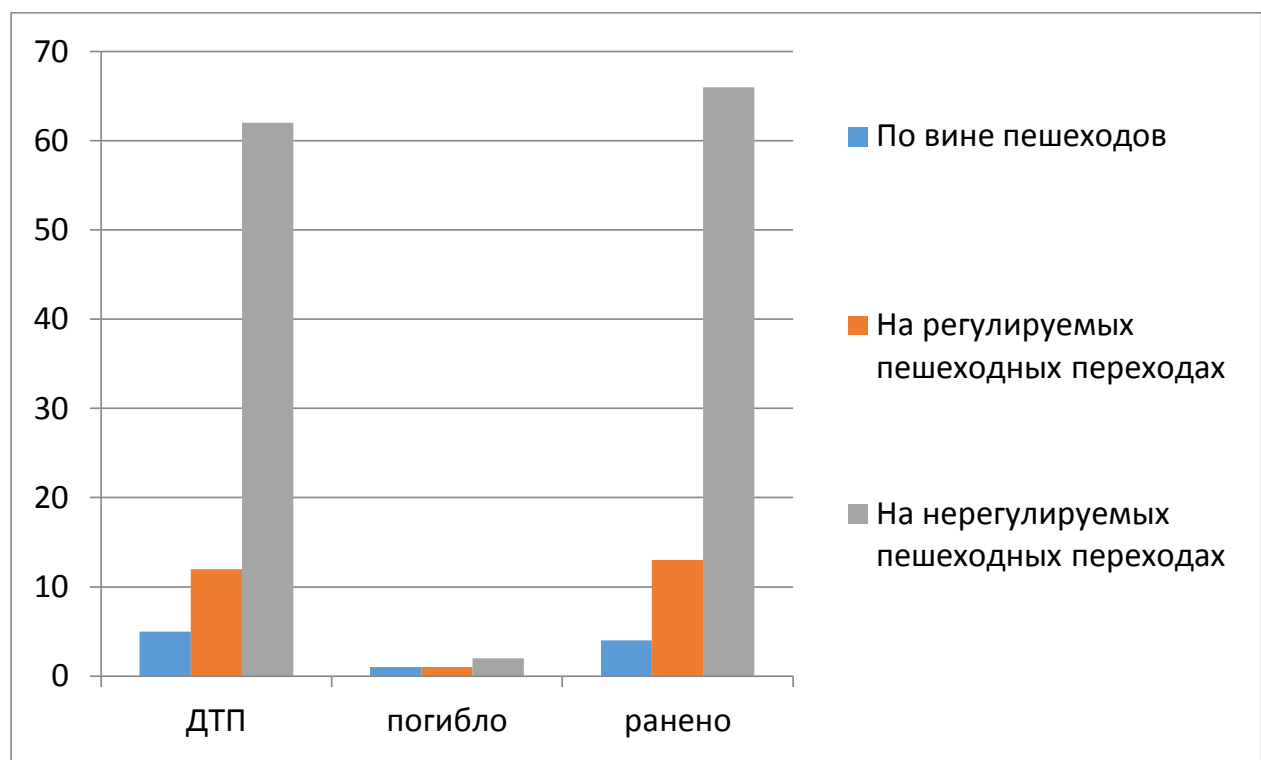

Рисунок 2 - Диаграммы ДТП. 


\begin{tabular}{|c|c|c|c|c|c|c|}
\hline Impact Factor: & $\begin{array}{l}\text { ISRA (India) } \\
\text { ISI (Dubai, UAI } \\
\text { GIF (Australia) } \\
\text { JIF }\end{array}$ & $\begin{array}{l}=1.344 \\
=0.829 \\
=0.564 \\
=1.500\end{array}$ & $\begin{array}{l}\text { SIS (USA) } \\
\text { PИНЦ (Russia } \\
\text { ESJI (KZ) } \\
\text { SJIF (Moroccc }\end{array}$ & $\begin{array}{l}=0.912 \\
=0.179 \\
=1.042 \\
=\mathbf{2 . 0 3 1}\end{array}$ & $\begin{array}{l}\text { ICV (Poland) } \\
\text { PIF (India) }\end{array}$ & $\begin{array}{l}=6.630 \\
=1.940\end{array}$ \\
\hline
\end{tabular}

Согласно анализу аварийности и правоприменительной деятельности наибольшее количество аварий и пресечённых административных правонарушений в отношении нетрезвых водителей в городе Тамбове в текущем году зарегистрировано на улицах Советской (4 ДТП, отстранены от управления 136 нетрезвых водителей) и Мичуринской (4 ДТП, отстранены от управления 140 нетрезвых водителей). По времени суток наибольшее количество административных правонарушений, допущенных нетрезвыми водителями, пресечено сотрудниками ГИБДД в период с 00 часов до 2 часов ночи.

Согласно данным зафиксированным 03.12. 2015 года.

По диаграмме дорожно-транспортных происшествий по дням недели видно, что пятница является наиболее травмоопасным днем.

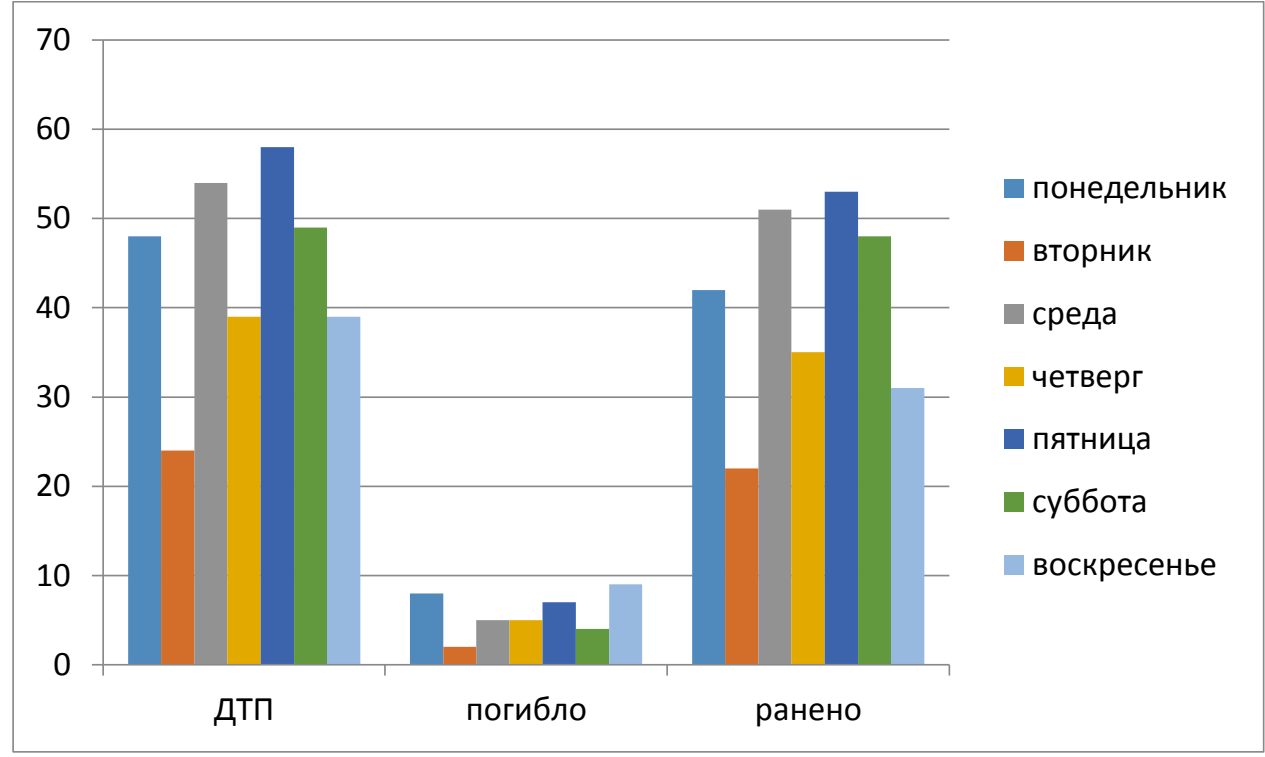

Рисунок 3 - Диаграммы аварийности по дням недели.

По приведенным данным можно сделать вывод, что количество ДТП уменьшается. Число погибших и раненых стало значительно меньше. Этот факт объясняется тем, что после ужесточения ответственности за нарушения ПДД, автомобилисты начали серьезнее относится к движению на автомобиле.

Для предотвращения ДТП были проведены следующие мероприятия.

Особое внимание уделяется оборудованию безопасных пешеходных переходов в районе школ, детских садов и учреждений дополнительного образования. В частности, устанавливаются светофоры импульсной индикации Т7, которые позволяют увеличивать видимость сигнала на расстоянии до 300 м и улучшать ее в непогоду.

В прошлом году такие светофоры были установлены около 31 школы, на пересечении улиц Б.Васильева и Тулиновской, около 28 лицея. В этом году мы продолжили эту работу и установили порядка 8 такихсветофорных объектов. Вопрос обеспечения безопасности в районе детских учреждений и учебных заведений администрация города Тамбова решает комплексно. Это и установка светофорных объектов, и нанесение горизонтальной дорожной разметки, установка искусственных дорожных неровностей, установка дорожных знаков «Ограничение скорости», «Внимание, дети». Сейчас порядка 90 процентов всех детских учебных заведений оборудованы всеми перечисленными средствами безопасности, сказал Андрей Игнатов, заместитель председателя комитета городского хозяйства администрации города Тамбова.

В этом году Тамбов, одним из первых в России реализовал пилотный проект по нанесению на центральных улицах горизонтальной дорожной разметки с использованием термопластика. Такая разметка появилась на улицах Интернациональной, Советской, Московской, Степана Разина, Карла Маркса, Чичканова. Термопластик позволяет значительно увеличить срок службы разметки и обеспечить её круглогодичную видимость. 


\begin{tabular}{l|lrl|l|ll} 
& ISRA (India) & $=\mathbf{1 . 3 4 4}$ & SIS (USA) & $=\mathbf{0 . 9 1 2}$ & ICV (Poland) & $=\mathbf{6 . 6 3 0}$ \\
Impact Factor: & ISI (Dubai, UAE) $=\mathbf{0 . 8 2 9}$ & PUHIL (Russia) $=\mathbf{0 . 1 7 9}$ & PIF (India) & $=\mathbf{1 . 9 4 0}$ \\
& GIF (Australia) & $\mathbf{0 . 5 6 4}$ & ESJI (KZ) & $=\mathbf{1 . 0 4 2}$ & & \\
& JIF & $=\mathbf{1 . 5 0 0}$ & SJIF (Morocco) $=\mathbf{2 . 0 3 1}$ & &
\end{tabular}

Работы по оборудованию пешеходных переходов в местах с повышенной аварийной опасностью и в районах новостроек продолжаются. Так, сейчас завершается оборудование регулируемого пешеходного перехода на пересечении улиц Мичуринской и Чичерина, который появился по многочисленным просьбам жителей. Там будет предусмотрена и дополнительная остановка общественного транспорта. В перспективе будут оборудованы еще три регулируемых пешеходных перехода в северной части - в районе пересечения улиц Мордасовой и Васильковой, Карла Маркса и Лысогорской и у 31-й школы по улице Социалистической. В этом году также запланирована установка светофорного объекта с выделенной пешеходной фазой на пересечении Бульвара Энтузиастов и улицы Социалистической.

\section{References:}

1. (2015) Tambovskaya oblast', zakon o programme sovershenstvovaniya i razvitiya seti avtomobil'nyh dorog Tambovskoj oblasti.

2. Aksenov IA (1980) Edinaya transportnaya sistema. Moscow: Transport, 1980. - 213 p.

3. Aksenenko BN (2000) Transport ob"edinyaet v edinyj kompleks vse otrasli ehkonomiki// Avtomobil'nyj transport, №1, 2000.

4. Babkov VF (1983) Avtomobil'nye dorogi. Moscow: Transport, 1983. 280 p.

5. Babkov VF, Andreev OV (1987) Proektirovanie avtomobil'nyh dorog. Moscow: Transport, 1987. $-368 \mathrm{p}$.

6. Vidyapin VI, Stepanova MV (1996) Territorial'naya organizaciya i razmeshchenie otraslej transporta/ Ekonomicheskaya geografiya Rossii 1996.
7. Voronin VV (1997) Ekonomicheskaya geografiya Rossijskoj Federacii, 1997.

8. Gladyuk YN, Dobrosyuk VA, Semenov SP (1999) Ekonomicheskaya geografiya transporta Rossii, 1999.

9. Gladkij YN, Dobrosyuk VA(1999) EHkonomicheskaya geografiya Rossii. Moscow: Gardarika, Literaturno - izdatel'skoe agentstvo Kafedra-M, 1999. -752p.

10. (2015) Available: http://www.gibdd.ru/ (Accessed: 20.12.2015).

11. (2015) Available: http://www.tambov.gov.ru/trans/roads.html (Accessed: 20.12.2015).

12. (2015) Available: http://investtambovregion.ru/? $\mathrm{p}=89$ (Accessed: 20.12.2015). 